\title{
A NOTE ON THE ACCURACY OF DISCRIMINA- TION OF WEIGHTS AND LENGTHS.
}

\section{BY PROFESSOR EDWARD L. THORNDIKE,}

Teachers College, Columbia University.

It is the purpose of this note to present some new data upon the very old question referred to by the title in the particular case of weights of Ioo and 200 grams and lines of 50, 75 and $100 \mathrm{~mm}$.

In spite of the repeated failure of experimental researches to verify the doctrine that the larger magnitude requires a proportionately larger difference for equal discriminability, that doctrine reappears so persistently in our text-books that it may be supposed to require further refutation.

The measurements with weights comprise 16 tests by the error method with each of 72 subjects. Eight were with a roogram standard and 8 with was to give the subject the standards and also some boxes identical with the standards, except that of course they were empty, and also a supply of lead scraps and shot. The subject filled an empty box, comparing it with the standard by lifting both simultaneously or successively as often as he chose, adding or taking out shot until he was satisfied. The experiments were conducted by Dr. Wilfrid Lay, a trained psychologist, and Mr.P. $R$. Dean, a student and teacher of physics. Counting of the shot was not done by the subjects and, of course, would not have been allowed. They worked in ignorance of the amounts of the errors they made. The subjects were 37 young women students of psychology and 25 high school boys.

In the nature of the case there were no important general tendencies to constant error since the subject compared his weight with the standard back and forth several times. With the 200-gram weight there was a slight tendency to a minus error because the subjects filled up to the weight oftener than they 
over-filled and corrected. The deviation from the standard is the measure (inverse) of accuracy of discrimination.

The general tendency is for the 200-gram weight to show an error $1.5^{85}$ times that of the 100. The probable Median Deviation of this result from the true general tendency is .04, Taking the 37 young women separately we have $1.65(.07)$. The figures are 1.52 and (.14) for the 25 high school boys.

Table I. gives for the 34 women the sum of the deviations from the standard for the 100-and 200-gram weights, the ratio

TABLE I.

\begin{tabular}{|c|c|c|c|c|c|}
\hline \multirow{2}{*}{ 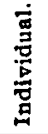 } & \multicolumn{2}{|c|}{ Sum of Deviations. } & \multirow{2}{*}{$\begin{array}{l}\text { Ratio of Error } \\
\text { with } 20 \mathrm{~g} \text { to } \\
\text { that with } 100 \mathrm{~g} \text {. }\end{array}$} & \multicolumn{2}{|c|}{$\begin{array}{l}\text { Apparent Median, Constant } \\
\text { Errors, with. }\end{array}$} \\
\hline & From $100 \mathrm{~g}$. & From $200 \mathrm{~g}$ & & $100 \mathrm{~g}$. & $200 \mathrm{~g}$ \\
\hline I & 96 & 58 & .60 & 2 & 4 \\
\hline 2 & 64 & 93 & 1.45 & 9 & -3 \\
\hline 3 & 45 & 94 & 2.09 & 5 & o \\
\hline 4 & 37 & 73 & 1.97 & 3 & \\
\hline 5 & 57 & 88 & 1.54 & -6 & -4 \\
\hline 6 & 48 & 76 & 1.58 & -5 & 0 \\
\hline 7 & $2 \mathrm{I}$ & 47 & 2.24 & & .5 \\
\hline 8 & 45 & 27 & 60 & -6 & \\
\hline 9 & 36 & I I I & 5.31 & 1.5 & -7.5 \\
\hline Io & 79 & 103 & $1.3 \sigma^{\circ}$ & 7.5 & 2.5 \\
\hline II & 24 & 96 & 4.00 & -1.5 & -3 \\
\hline 12 & 55 & 91 & 1.65 & 2.5 & -6.5 \\
\hline I3 & $2 \mathrm{I}$ & 43 & 2.05 & 0 & -2 \\
\hline$I_{4}$ & I5 & 82 & 5.47 & 0 & -8 \\
\hline I.5 & 43 & 85 & I.98 & o & 1.5 \\
\hline 16 & $4 I$ & 65 & 1.59 & 3 & 9 \\
\hline I7 & 52 & 103 & 1.98 & -6 & -12.5 \\
\hline 18 & 21 & 46 & 2.19 & -1.5 & -3.5 \\
\hline 19 & 28 & IIo & 3.93 & 1.5 & -3.5 \\
\hline 20 & 75 & 89 & 1.19 & 3.5 & -8 \\
\hline $2 \pi$ & 52 & 160 & 3.08 & -2 & -19 \\
\hline 22 & 48 & 76 & 1.58 & -6 & -8.5 \\
\hline 23 & 104 & 74 & $.7 \mathrm{I}$ & -3 & I \\
\hline 24 & 25 & 72 & 2.88 & 2 & -5 \\
\hline 25 & $I I \bar{I}$ & 118 & 1.06 & 16 & -8 \\
\hline 26 & 33 & 55 & 1.67 & 0 & -5.5 \\
\hline 27 & 48 & 78 & 1.63 & 2 & 10.5 \\
\hline 28 & 37 & $5^{6}$ & I.5I & 3 & -1.5 \\
\hline 29 & 52 & 77 & 1.48 & 7.5 & .5 \\
\hline 30 & 56 & 73 & I.3I & I.5 & 3.5 \\
\hline 3 I & 93 & 58 & .62 & .5 & 2 \\
\hline 32 & 28 & 50 & 1.79 & 0 & .5 \\
\hline 33 & 100 & 214 & 2.14 & -12 & -29 \\
\hline 34 & 34 & 58 & $1.7 \mathrm{I}$ & I. 5 & $=I$ \\
\hline 35 & 68 & 148 & 2.18 & 3 & \\
\hline 36 & I57 & 169 & 1.08 & 29 & -8 \\
\hline 37 & 42 & 25 & .60 & 4 & -2 \\
\hline
\end{tabular}

Median of ratios $=\mathbf{x} .65$. 
of the latter to the former and the apparent constant errors for the two sets, all for each individual. The last facts are given to show the impropriety of using the deviation from an individual's own general plus or minus tendency as a measure of discrimination.

Table II. gives similar facts for the 25 boys, except that here the sums of deviations were taken from the general tendency of $198 \mathrm{~g}$. instead of from $200 \mathrm{~g}$. Two hundred grams would have been better to use, but as it makes no difference in the general results, I have not recalculated all the deviations.

TABLE II.

\begin{tabular}{|c|c|c|c|c|c|}
\hline \multirow{2}{*}{ 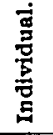 } & \multicolumn{2}{|c|}{ Sum of Deviations. } & \multirow{2}{*}{$\begin{array}{l}\text { Ratio of Error } \\
\text { writh } 2 \infty \infty \mathrm{g} \text {. to } \\
\text { that with } 100 \mathrm{~g} \text {. }\end{array}$} & \multicolumn{2}{|c|}{$\begin{array}{c}\text { Apparent Average, Constant } \\
\text { Errors, with: }\end{array}$} \\
\hline & From $300 \mathrm{~g}$ & From $198 \mathrm{~g}$. & & $100 \mathrm{~g}$ & $200 \mathrm{~g}$. \\
\hline $\begin{array}{l}38 \\
39 \\
40 \\
41 \\
42 \\
43 \\
44 \\
45 \\
46 \\
47 \\
48 \\
49 \\
50 \\
51 \\
52 \\
53 \\
54 \\
55 \\
56 \\
57 \\
58 \\
59 \\
60 \\
61 \\
62\end{array}$ & $\begin{array}{r}40 \\
40 \\
37 \\
35 \\
65 \\
53 \\
90 \\
103 \\
44 \\
63 \\
28 \\
33 \\
55 \\
34 \\
113 \\
33 \\
46 \\
33 \\
62 \\
36 \\
49 \\
65 \\
62 \\
23 \\
79\end{array}$ & $\begin{array}{r}60 \\
66 \\
24 \\
53 \\
73 \\
264 \\
161 \\
91 \\
80 \\
96 \\
40 \\
84 \\
53 \\
36 \\
108 \\
61 \\
72 \\
80 \\
94 \\
45 \\
109 \\
138 \\
72 \\
73 \\
97\end{array}$ & $\begin{array}{r}1.50 \\
1.65 \\
.65 \\
1.51 \\
1.12 \\
4.98 \\
1.79 \\
.88 \\
1.82 \\
1.52 \\
1.43 \\
2.55 \\
.96 \\
1.06 \\
.96 \\
1.85 \\
1.57 \\
2.43 \\
1.52 \\
1.25 \\
2.22 \\
2.12 \\
1.16 \\
3.17 \\
1.23\end{array}$ & $\begin{aligned}-2 \\
2 \\
-4.5 \\
1 \\
7 \\
-6 \\
3 \\
-8.5 \\
-4 \\
6.5 \\
2.5 \\
-4 \\
-7 \\
-1 \\
13 \\
-1 \\
-2 \\
0 \\
0 \\
7.5 \\
-.5 \\
0 \\
-7 \\
8 \\
-8\end{aligned}$ & 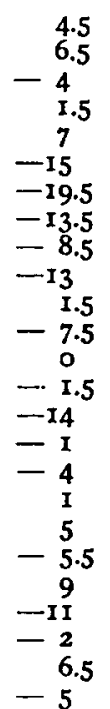 \\
\hline
\end{tabular}

Median of ratios $=1.52$.

My measurements with lines comprise 60 tests with each of 37 individuals - 30 in drawing a line at one side of a $100-\mathrm{mm}$. standard as nearly as possible equal to it, and 30 in equalling in the same way a $50 \mathrm{~mm}$. standard. The individuals tested were the students of psychology mentioned above, and the tests were conducted by Dr. Lay. 
Table III. presents the results in the shape of (I) the sum of the deviations from the standard, (2) the general tendency to draw too long or too short lines (the so-called constant error) and (3) the so-called variable error, that is, the general tendency to deviate from the individual's own general tendency to draw too long or too short lines (the measure used for this variable error is the distance between the limits which include 50 per

Table III.

\begin{tabular}{|c|c|c|c|c|c|c|c|c|}
\hline \multirow{2}{*}{ } & \multicolumn{2}{|c|}{$\begin{array}{l}\text { Sums of Deviations } \\
\text { from the Standards. }\end{array}$} & \multicolumn{2}{|c|}{$\begin{array}{l}\text { B. } \\
\text { So-called Constant } \\
\text { Errors }\end{array}$} & \multicolumn{2}{|c|}{$\begin{array}{c}\text { C } \\
\text { So-called Variable } \\
\text { Errors }(2 \times Q) .\end{array}$} & \multirow{2}{*}{$\begin{array}{c}\text { D } \\
\text { Ratios } \\
\text { 1o/so } \\
\text { frow } \\
\text { A. }\end{array}$} & \multirow{2}{*}{\begin{tabular}{|c} 
E. \\
Ratios \\
Ioo/so \\
froun \\
C.
\end{tabular}} \\
\hline & $\begin{array}{c}\text { From } 50 \\
\text { mm. }\end{array}$ & $\underset{\substack{\text { Fm } \\
\text { From }}}{100}$ & $\underset{\mathrm{mm}}{\text { From }}$ 50 & $\begin{array}{c}\text { From } 1 \infty \\
\text { mm. }\end{array}$ & $\begin{array}{l}\text { In case of } \\
\text { so mm. }\end{array}$ & $\begin{array}{l}\text { In case of } \\
\text { 100 } \mathrm{mm}\end{array}$ & & \\
\hline I & 166 & I 59 & 0 & 3.5 & 8 & 8 & 1.37 & 1.00 \\
\hline 2 & $9^{1}$ & 232 & 1.5 & 8 & 6 & 5 & 2.55 & $1 . \infty$ \\
\hline 3 & 51 & 138 & 0 & 4 & 4 & 8 & 2.71 & 2.00 \\
\hline 4 & 57 & 77 & I & 2 & 4 & 4 & I. 35 & 2.00 \\
\hline 5 & 138 & I70 & 4 & -2 & 4 & 6.5 & 1.23 & 1.63 \\
\hline 6 & 108 & 359 & 2 & I 2 & 5 & 10 & 3.32 & 2.00 \\
\hline 7 & 90 & 79 & -2 & I & 2 & 5 & .88 & 2.50 \\
\hline 8 & 56 & 130 & 0 & 3 & 4 & 6 & 2.32 & 1.50 \\
\hline 9 & IIO & 289 & 2 & 6 & 5 & 16 & 2.63 & 3.20 \\
\hline 10 & 115 & 242 & 3.5 & 8.5 & 4 & 5 & 2.10 & 1.25 \\
\hline II & 80 & 204 & 2 & 6 & 5 & 6 & 2.55 & 1.20 \\
\hline 12 & III & 234 & 1.5 & 8 & 5 & 6 & 2.11 & 1.20 \\
\hline 13 & 75 & 124 & 2.5 & 4 & 4 & 2 & 1.65 & .50 \\
\hline$x_{4}$ & II 5 & 122 & -3 & 2.5 & 4 & 8 & 1.06 & 2.00 \\
\hline I5 & $8 I$ & 86 & -3 & 0 & 3 & 7 & 1.06 & 2.33 \\
\hline 16 & 94 & I5I & I & 4 & 7 & 6 & $1.6 \mathrm{r}$ & .86 \\
\hline 17 & 118 & 135 & -4 & 5 & 3 & 4 & 1.14 & 1.33 \\
\hline 18 & 80 & 198 & $-\mathrm{I} .5$ & 0 & 4 & 15 & 2.47 & 3.75 \\
\hline 19 & 66 & 148 & I & 4 & 4 & 6 & 2.24 & 1.50 \\
\hline 20 & 79 & 203 & .5 & 6 & 6 & 8 & 2.57 & 1.33 \\
\hline $2 I$ & 122 & 198 & -1.5 & -5 & 10 & 7 & 1.62 & .70 \\
\hline 22 & 45 & 97 & 2 & 2 & 2 & 4 & I.02 & 2.00 \\
\hline 23 & 89 & II 3 & 3 & 3 & 3 & 4 & 1.27 & 1.33 \\
\hline 24 & 253 & 459 & 8 & 15 & 5 & 5 & I. 81 & 1.00 \\
\hline 25 & 181 & 220 & 6 & 7.5 & 5 & 5 & I.22 & 1.00 \\
\hline 26 & 90 & 193 & $-r$ & 5 & 6 & 7 & 2.16 & 1.17 \\
\hline 27 & 138 & IIO & -4.5 & -.5 & 5 & 8 & .80 & 1.60 \\
\hline 28 & 69 & 66 & 2 & 2 & 4 & 4 & .96 & 1.00 \\
\hline 29 & 76 & 297 & -I & 9.5 & 4 & 7 & 3.91 & 1.75 \\
\hline 30 & 167 & 154 & -5 & I. 5 & I0 & 12 & .92 & 1.20 \\
\hline 31 & 83 & 183 & o & 6 & 6 & 6 & 2.21 & 1.00 \\
\hline 32 & 74 & $14 \mathrm{I}$ & 2 & 2 & 2 & 5 & I.9I & 2.50 \\
\hline 33 & I35 & 202 & 4 & 5 & 5 & 8 & I.5O & 1.60 \\
\hline 34 & II2 & 222 & 3 & 7 & 3 & 6 & 1.98 & 2.00 \\
\hline 35 & I7I & $33 \mathrm{I}$ & 6 & 11.5 & 3 & 4 & 1.94 & 1.33 \\
\hline 36 & 245 & 329 & 8.5 & 10 & 5 & I I & 1.34 & 2.20 \\
\hline 37 & 63 & 160 & I & 5.5 & 5 & 5 & 2.54 & 1.00 \\
\hline
\end{tabular}

Wedians of ratios are $x .81$ and $x .33$.

$\Delta$ verages of ratios $=1.79$ and $\mathbf{1 . 4 2}$. 
cent. of his records), (4) the $100 / 50$ ratio in the case of the deviations from the standard, and (5) the $100 / 50$ ratio in the case of the deviations from the so-called 'constant error.'

As has been pointed out by Professor Cattell, the so-called constant error is really extremely variable in the case of equalling lines. It is a result of short-lived motor or perceptual habits as well as of some persistent tendency. It is sensitive to practice. It differs enormously with individuals. The practice of disregarding it in measuring the accuracy of sense discrimination is therefore dubious. When we disregard it, we do not have left a measure of accuracy in any intelligible sense, but strictly only a measure of the variability of an individual in responding to the same situation.

It is not, however, my purpose at this time to interpret the errors made, but only to point out that, whatever measure one chooses to take of inaccuracy of sense discrimination, the inaccuracy is not proportional to the magnitude used as a standard. The deviations from the standard are not twice as great for the I00-mm. line as for the 50, but only one and three fourths times as great $[\mathrm{I} .8 \pm . \mathrm{I}$ (P.E.)]. And the so-called variable error in the case of the $100-\mathrm{mm}$. line is only one and one third times that with the 40-mm. line [ $.4 \pm .08$ (P.E.)]. If each individual's deviations from the constant error of the entire 37 are used, the ratio is still less than one and a half.

The variations of the individuals from the central tendency of the group are very wide in the case of both weights and lines. There is nothing like close clustering of the individual ratios about I.6 in the former, or I.8 and I.4 in the latter case.

I attribute the results in general not to one main cause, in the shape of some one psycho-physic law, varied by minor disturbing causes, but to the influence of many specialized tendencies to response. The individual scores for the weights, coming each from only 8 measures, are subject to much variation from the totals of which they are samplings. Tests covering hundreds of trials spread over many days would reduce the individual differences in the $200 /$ Ioo ratios markedly. But it is hard to believe that such would reduce them to a range much less than $I 90$ to I30. The individual scores for the lines are more reliable and 
rough calculation of their reliabilities shows the practical certainty that with complete measures there would remain a range of variation, around the I.8, of from 1.5 to 2.3 and a range, around the I.4, of I.I5 to I.75.

In general the determinations of the so-called psycho-physic law have failed to find close correspondence in the different individuals measured or in the different divisions of the magnitudeseries used. It is chiefly the speculative doctrine that some one simple equating of sensations or judgments with magnitudes judged must exist and be the main cause of our powers to judge them that has led psychologists to neglect these failures. But against such a doctrine stand (I) the facts of the changes in these powers with practice, (2) their specialization with content, and (3) the difficulty of connecting the doctrine with the known facts about the action of the nervous system, as well as (4) the direct measurement of the variations amongst individuals. The present writer believes not only that the experimental data do not give proof of the existence of any one psycho-physic law, but also that they do give proof that there is not any such one law.

An objection may be made to the original measurements themselves: namely, that they are extremely complex measures of discrimination resulting from all sorts of conditions. This is true, in the sense that the judgment of weight was allowed to rest upon liftings in any number, at any rate, with either hand, and that the judgments of length were allowed to rest upon data from the movements made in drawing the lines or from the sight of them at varying distances while being drawn and after completion. But it is not necessarily true if complexity means elaborateness from the point of view of the individual making the judgment or with respect to the behavior of the nervous system in making such responses. To have to lift weights at the same rate through the same distance by a time schedule may be a more complex act. because of the inhibitions involved, than the act in the case of my experiments.

But in either event the method is not really objectionable. If the law in question held for the responses when made to each single constant kind of sense datum, it would necessarily hold 
for any responses to any random combination of such. The particular accuracies might vary, but the general law would appear as before. So, unless the critic can give evidence that the subjects chose specially accurate data from which to judge the $200 \mathrm{~g}$. weights and specially inaccurate data from which to judge the roo g. weights, the objection is futile.

The writer chose the method deliberately because it seems to him sure that accuracy in sense-discriminations has developed as a function of responses to concrete objects with all the available means at the animal's disposal, and that the laws regulating it will relate more closely to such instinctive responses and the habits they easily grow into than they will to the rare and artificial responses we cultivate by restricting the situation ostensibly to some one element, but really to that element in an elaborate context of distracting suggestions and inhibitions. 